Check for updates

Cite this: RSC Adv., 2018, 8, 41032

Received 27th October 2018

Accepted 22nd November 2018

DOI: $10.1039 / \mathrm{c} 8 \mathrm{ra0} 8900 \mathrm{k}$

rsc.li/rsc-advances

\title{
Preparation and characterization of novel forward osmosis membrane incorporated with sulfonated carbon nanotubes $\uparrow$
}

\begin{abstract}
Yonghao Li, ${ }^{\text {ab }}$ Yuntao Zhao, ${ }^{\text {ab }}$ Enling Tian (D) *ab and Yiwei Ren*abc
In this study, carbon nanotubes (CNTs) were modified with sulfonated groups and incorporated into the active layer of a forward osmosis (FO) membrane to achieve a desirable thin-film nanocomposite (TFN) FO membrane. Different concentrations of sulfonated carbon nanotubes (SCNTs) were added, and their impact on the FO membrane was also investigated, including the hydrophilicity, roughness, membrane morphology and FO performance. With the addition of SCNTs, the membrane surface got smoother and denser, and the hydrophilicity also improved significantly. Regarding FO performance, SCNTsfunctionalized FO membranes exhibited higher water flux $\left(J_{w}\right)$ and lower reverse salt flux $\left(J_{s}\right)$. The optimal $J_{w}$ of $29.9 \pm 1.6 \mathrm{LMH}$ was achieved by using $1 \mathrm{M} \mathrm{NaCl}$ solution as the draw solution (DS) and deionized (DI) water as the feed solution (FS), almost 140\% higher than the control (21.3 $\pm 2.1 \mathrm{LMH})$ and $J_{\mathrm{s}}$ decreased to about $12 \%$.
\end{abstract}

\section{Introduction}

Recently, forward osmosis (FO), as a novel membrane separation technique, has attracted significant attention in academic and industrial fields. ${ }^{\mathbf{1 , 2}}$ Unlike pressure-driven membrane processes such as ultrafiltration (UF), nanofiltration (NF) and reverse osmosis (RO), FO utilizes the osmosis pressure gradient as the driving force to extract water across the membrane from the feed solution (FS) to the concentrated draw solution (DS). ${ }^{3}$ Except for low energy consumption, ${ }^{4}$ FO has a higher water recovery rate $^{5}$ and lower fouling propensity ${ }^{6}$ as it is operated under no or low hydraulic pressure. Based on the above advantages, FO technology has developed rapidly during these years and has exhibited many potential applications in waste water treatment, ${ }^{7,8}$ desalination, ${ }^{4}$ food processing, ${ }^{9}$ power generation $^{\mathbf{1 0}}$ etc.

There is no doubt that FO membrane is the heart of FO technology. To achieve a desirable FO separation performance (system), an FO membrane should have great qualities such as high water flux, high salt rejection, good stability and favorable

${ }^{a}$ Key Laboratory of Reservoir Aquatic Environment, Chongqing Institute of Green and Intelligent Technology, Chinese Academy of Sciences, No. 266 Fangzheng Avenue, Shuitu Hi-tech Industrial Park, Shuitu Town, Beibei District, Chongqing, 400714, China.E-mail: tianenling@cigit.ac.cn; 945693790@qq.com; 378367317@qq.com; Fax: +86 023-65935806; Tel: +86 023-65935825

${ }^{b}$ University of Chinese Academy of Sciences, Beijing 100049, China

${ }^{c}$ Department of Chongqing Industrial Technology Innovation Institute of Environmental Protection Membrane Materials and Equipment Technology, Wangu Industrial Development, Dazu District, Chongqing, 402360, China

† Electronic supplementary information (ESI) available. See DOI: 10.1039/c8ra08900k anti-fouling property. ${ }^{\mathbf{1 1}}$ Extensive efforts have been made to meet the aforementioned requirements. Either physical modification $^{\mathbf{1 2}}$ or chemical functionalization ${ }^{\mathbf{1 3}}$ has been proven to be effective to enhance the performance of FO membrane. Nevertheless, some conventional problems still exist, such as low water flux and high reverse salt flux, which hinders the development and application of FO membrane. Besides, internal concentration polarization has also been a major problem when asymmetric thin-film composite (TFC) membrane was used for FO.

To overcome this problem, with the progress of nanotechnology, many researchers have devoted to using nanostructured materials to enhance the properties of FO membranes. ${ }^{\mathbf{1 4}}$ Graphene Oxide (GO) is regarded as an excellent additive and is widely employed as an additive on the surface of FO membranes..$^{15,16}$ It was reported that GO-incorporated FO membranes acquired higher water flux, enhanced hydrophilicity and better anti-fouling property. ${ }^{15}$ In addition, some other nanomaterials such as metal organic framework (MOF), ${ }^{17}$ zeolites, ${ }^{18} \mathrm{TiO}_{2}{ }^{19}$ and carbon nanotubes $(\mathrm{CNTs})^{20}$ have also been incorporated into FO membranes. Among them, CNTs showed great potential in the membrane separation area due to their one-dimensional nanostructure and unique transmission performance. ${ }^{21}$ Besides, CNTs own properties such as antibacterial property, chlorine resistance and inoxidizability. ${ }^{22,23}$ Therefore, they have been widely employed and incorporated into the substrate or active layer of thin-film composite (TFC) FO membranes.

However, low hydrophilicity has become a major problem, which hinders CNTs' application in membrane modification. Pure CNTs have poor solubility in water and can hardly improve 
FO membrane's performance if not functionalized. In previous researches, amino ${ }^{24}$ and carboxylic ${ }^{23}$ CNTs have already been employed to modify FO membranes and both have turned out to be effective. Therefore, functionalized CNTs were considered to be remarkable additives for FO membranes. Since the polarity of the sulfonic group is stronger than that of an amidogen or carboxyl group, sulfonated carbon nanotubes (SCNTs)modified FO membranes were supposed to own better hydrophilicity and FO performance.

In this study, CNTs were successfully sulfonated, and the assynthesized SCNTs were used to modify the polyamide (PA) layer of FO membrane. To the best of our knowledge, SCNTs have never been applied, either to the substrate or PA layer, in the preparation of FO membranes. Besides, the properties of novel thin-film nanocomposite (TFN) FO membranes were systematically investigated and were compared with the unmodified membrane.

\section{Materials and methods}

\subsection{Materials}

Polysulfone (PSF) beads (Udel P-3500, 77 000-83 $000 \mathrm{~g} \mathrm{~mol}^{-1}$, Solvay) were used for fabricating the membrane substrate. Carbon nanotubes (OD: 4-6 nm, length: $50 \mu \mathrm{m}$, >98\%) were purchased from Chengdu Organic Chemistry co. LTD of Chinese Academy of Sciences. Dimethylacetamide (DMAc, $>99 \%$, Merck) was used as the solvent. $m$-Phenylenediamine (MPD, 98\%, TCI), 1,3,5-benzene-tricarbonyl trichloride (TMC, $98 \%$, TCI) and $n$-hexane (>99\%, Merck) were all employed for interfacial polymerization (IP). Nitric acid ( $\mathrm{HNO}_{3}, 70 \%$, Merck), vitriol $\left(\mathrm{H}_{2} \mathrm{SO}_{4}, 98 \%\right.$, Merck), ammonium persulfate $\left(\left(\mathrm{NH}_{4}\right)_{2} \mathrm{~S}_{2} \mathrm{O}_{8}\right.$, $>98$, Kelong) and sodium polystyrene sulfonate (PSS, 99\%, Kelong) were employed for modifying CNTs. Sodium chloride ( $\mathrm{NaCl}, 99.5 \%$, KeLong) and deionized (DI) water $(18.25 \mathrm{M} \Omega \mathrm{cm}$, Molecular $\Sigma \mathrm{H}_{2} \mathrm{O}$ ) were used in the FO test.

\subsection{Synthesis of SCNTs}

Schematic of CNT's reaction process is shown in Fig. S1 (ESI $\dagger$ ). First, pure CNTs were added into a mixture of $\mathrm{HNO}_{3}$ and $\mathrm{H}_{2} \mathrm{SO}_{4}$ solution, and then heated to $80{ }^{\circ} \mathrm{C}$ for $8 \mathrm{~h}$. The treated CNTs were washed with DI water, filtered and then dried to obtain carboxyl carbon nanotubes (CCNTs). Subsequently, CCNTs were treated by in situ radical polymerization of PSS to achieve the final SCNTs according to the method reported in the previous literature. ${ }^{25}$ CCNTs were vigorously stirred in a mixture of sodium PSS and DI water at room temperature for $10 \mathrm{~h}$. Following that, $\left(\mathrm{NH}_{4}\right)_{2} \mathrm{~S}_{2} \mathrm{O}_{8}$ was added, and the mixture was heated to $65{ }^{\circ} \mathrm{C}$ under stirring to initiate the reaction. After cooling to room temperature, the mixture was diluted with $100 \mathrm{ml}$ DI water, and then washed repeatedly with DI water before sonication for $0.5 \mathrm{~h}$. The mixture was filtered and mixed with $4 \mathrm{M} \mathrm{H}_{2} \mathrm{SO}_{4}$, and then stirred at room temperature for $24 \mathrm{~h}$ to transform SCNTs from $\mathrm{Na}^{+}$form to $\mathrm{H}^{+}$form. Finally, the mixture was filtered and washed several times with DI water until the $\mathrm{pH}$ remained unchanged and then dried at $120^{\circ} \mathrm{C}$ for $12 \mathrm{~h}$.

\subsection{Preparation of TFN FO membranes}

The support layer was prepared via a traditional phase inversion method. In brief, PSF beads (15 wt\%) were dissolved in DMAc at room temperature for $24 \mathrm{~h}$. After degassing for one day, the casting solution was homogeneously spread on a clean glass plate with a casting knife of $100 \mu \mathrm{m}$ thickness, and then immediately immersed into a water coagulation bath. After preliminary phase separation, the nascent membrane was transferred into the water coagulation bath and was left there for 2 days with water changed every $12 \mathrm{~h}$ to remove the residual solvents.

The active layer of the membrane was formed on the surface of PSF substrate through IP. SCNTs were diluted in $2 \mathrm{wt} \%$ MPD solution with concentrations of 0-600 ppm, and then ultrasonicated for $1 \mathrm{~h}$ to exfoliate the SCNTs. In the IP process, first, the MPD aqueous solution containing SCNTs was poured onto the surface of PSF substrate for $2 \mathrm{~min}$. Excess solution was removed by nitrogen. Then, $0.15 \%$ TMC $n$-hexane solution was poured onto the surface of the membrane for $1 \mathrm{~min}$. Subsequently, the membrane was rinsed with $n$-hexane to remove excessive TMC and stored in an oven at $70{ }^{\circ} \mathrm{C}$ for $4 \mathrm{~min}$. Finally, the membrane was stored in DI water until it was tested. According to the concentration of SCNTs $(0 \mathrm{ppm}, 100 \mathrm{ppm}$, $200 \mathrm{ppm}, 400 \mathrm{ppm}$ and $600 \mathrm{ppm}$ ), the membrane was marked as TFC, TFN-1, TFN-2, TFN-4 and TFN-6.

\subsection{Characterization of SCNTs}

The as-synthesized SCNTs were characterized using Fourier transform infrared spectroscopy (FTIR, Agilent Cary 630) with wavenumber of $600-3000 \mathrm{~cm}^{-1}$ to estimate the functional groups. Thermogravimetric analysis (TGA, Thermo Scientific) was performed to further confirm whether the polystyrene sulfonic acid groups were grafted onto the CNTs from $30^{\circ} \mathrm{C}$ to $600{ }^{\circ} \mathrm{C}$ at a heating rate of $10{ }^{\circ} \mathrm{C} \mathrm{min}^{-1}$.

\subsection{Characterization of FO membranes}

The surface morphological properties of the FO membranes were observed using a field emission scanning electron microscope (FESEM, JSM-7800F, JEOL). All the membrane samples were coated with gold by a sputter coater before observation. The water contact angle (CA) of the membranes was measured with a contact angle goniometer (DSA100, KRÜSS) by the sessile drop method, and all data were calculated as an average of at least 5 points. To estimate the functional groups of the membrane surface, infrared spectra of the membranes were obtained through FTIR. Before testing, the membranes were dried in an oven at $80{ }^{\circ} \mathrm{C}$ for $12 \mathrm{~h}$. In addition, the surface roughness of the membranes was investigated using atomic force microscope (AFM, Thermo Scientific) under tapping mode in the air. To further testify the stability of SCNTs inside the membranes, X-ray photoelectron spectroscopy (XPS, Thermo Scientific) was used to characterize the PA layer of FO membranes, which included carbon (C), nitrogen (N), oxygen (O) and sulfur (S). 


\subsection{Determination of FO performance}

The FO performance of the membranes was determined by a lab-scale cross-flow FO system. The effective area of a membrane cell was $18 \mathrm{~cm}^{2}$, and all membranes were tested under FO mode with the active layer facing FS. FS and DS were DI water and $\mathrm{NaCl}$ aqueous solution of four different concentrations $(0.5 \mathrm{M}, 1 \mathrm{M}, 1.5 \mathrm{M}$ and $2 \mathrm{M})$, which were circulated by two peristaltic pumps at the same flow speed of $108 \mathrm{rpm}$. The conductivity of FS was automatically recorded by a conductivity meter and the weight of DS was collected with a digital balance. All membranes were tested at $25^{\circ} \mathrm{C}$ using a water circulator, and the tests were repeated for 3 times to obtain the average value. Water flux $\left(J_{\mathrm{w}}, \mathrm{L} \mathrm{m}^{-2} \mathrm{~h}^{-1}\right.$ or $\left.\mathrm{LMH}\right)$ and reverse salt flux $\left(J_{\mathrm{s}}, \mathrm{g} \mathrm{m}^{-2}\right.$ $\mathrm{h}^{-1}$ or $\mathrm{g} \mathrm{MH}$ ) were calculated by the following eqn.

$$
J_{\mathrm{w}}=\frac{\Delta V}{A_{\mathrm{m}} \Delta t}
$$

where $\Delta V(\mathrm{~L})$ is the permeate water volume over a period $\Delta t(\mathrm{~h})$, and $A_{\mathrm{m}}\left(\mathrm{m}^{2}\right)$ is the test area of FO membrane. The water density was supposed to be $1000 \mathrm{~g} \mathrm{~L}^{-1}$.

$$
J_{\mathrm{s}}=\frac{C_{t} V_{t}}{A_{\mathrm{m}} \Delta t}
$$

where $C_{t}\left(\mathrm{~g} \mathrm{~L}^{-1}\right)$ is the FS concentration over $\Delta t$ and $V_{t}(\mathrm{~L})$ is the volume of FS over $\Delta t$. The $C_{t}$ was determined by a standard curve of salt concentration and conductivity. $A_{\mathrm{m}}\left(\mathrm{m}^{2}\right)$ is the effective membrane area.

\subsection{Evaluation of membrane intrinsic properties}

The intrinsic properties of all FO membranes, including water permeability $(A)$ and salt permeability $(B)$, were calculated by a standard testing method. ${ }^{26}$

\section{Results and discussion}

\subsection{Characterization of SCNTs}

Successful synthesis of SCNTs was determined by FTIR, as shown in Fig. 1. The appearance of characteristic peaks at $1058 \mathrm{~cm}^{-1}$ and $1250 \mathrm{~cm}^{-1}$ can be attributed to the symmetric and asymmetric stretching of $\mathrm{O}=\mathrm{S}=\mathrm{O}$, and the band at $1400 \mathrm{~cm}^{-1}$ was also attributed to the sulfonic acid group. The peak at $880 \mathrm{~cm}^{-1}$ corresponds to the absorption of para substitution of benzene ring which derives from PSS. ${ }^{27}$ The above-mentioned absorption peaks can be ascribed to the functional groups of sulfonated polystyrene, which confirms that the sulfonic acid group had been grafted onto the CNTs successfully. To further prove this, TGA was performed. Pure CNTs showed a steady weight loss between $30{ }^{\circ} \mathrm{C}$ and $600{ }^{\circ} \mathrm{C}$, while SCNTs had a significant weight loss after $140^{\circ} \mathrm{C}$, as shown in Fig. 2. It can be explained that except for the terminal groups such as $-\mathrm{COOH}$ at the defective sites of CNTs that disintegrated slowly as the temperature increased, the sharper curve can be ascribed to the decomposition of the grafted sulfonic group on SCNTs, which is in agreement with the FTIR results. ${ }^{25}$

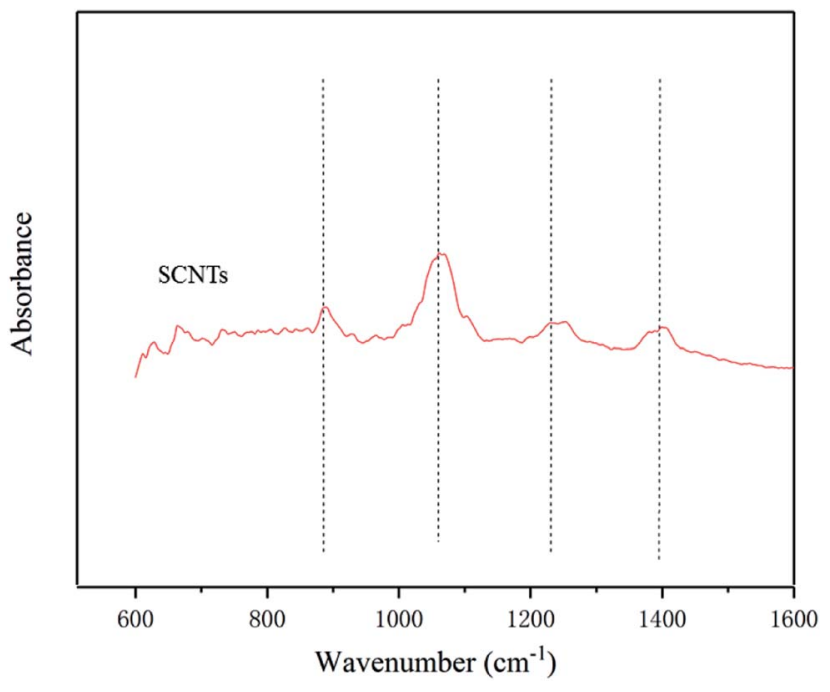

Fig. 1 FTIR spectra of SCNTs.

\subsection{Characterization of SCNTs-modified FO membranes}

Previous researches have proved that incorporating carbon nanomaterials into the PA layer of FO membrane is favorable to improve FO membrane's hydrophilicity and enhance its osmosis performance. ${ }^{15,24}$ Based on this, CNTs were adopted. The surface morphologies of FO membranes are clearly depicted in the SEM images (Fig. 3). The PA layer of all membranes, which was formed by MPD and TMC in the IP process, had a typical structure of ridge-valley, indicating that the active layer was truly coated onto the PSF substrate. In comparison with the unmodified FO membrane (Fig. 3(a)), the SCNTs-functionalized FO membrane exhibited denser and smoother surface structure with the increase in SCNTs content (Fig. 3(b)-(e)), which proved that the addition of SCNTs had a significant impact on the membrane's morphology. When SCNTs were incorporated into the PA layer, the reaction speed of MPD and TMC was hindered slightly because SCNTs in the MPD solution aggregated and



Fig. 2 TGA curves of SCNTs and CNTs. 

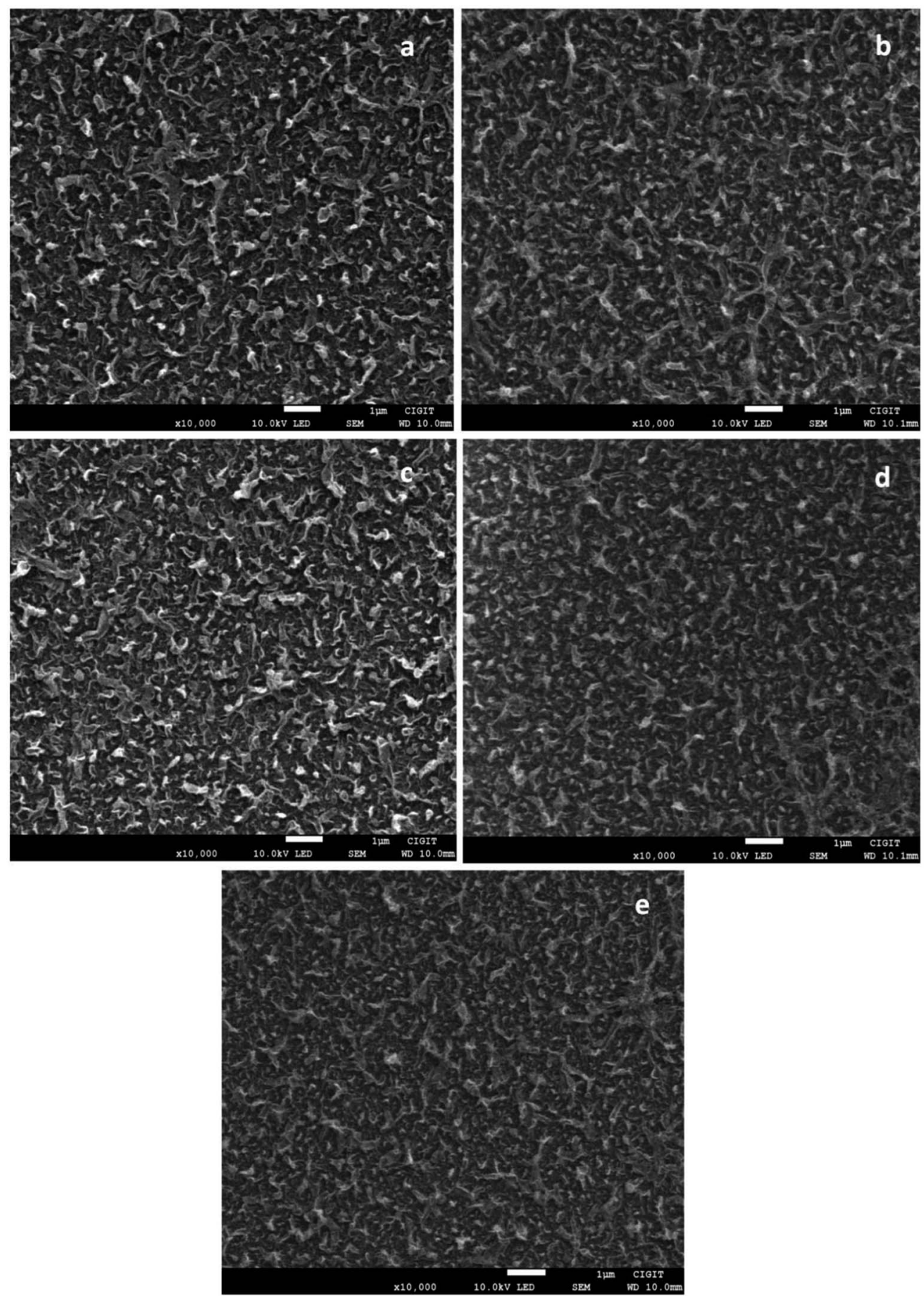

Fig. 3 SEM images of (a) TFC, (b) TFN-1, (c) TFN-2, (d) TFN-4 and (e) TFN-6 FO membranes.

Table 1 XPS results of TFC and TFN membranes

\begin{tabular}{llcll}
\hline Membranes & $\mathrm{C}(\%)$ & $\mathrm{N}(\%)$ & $\mathrm{O}(\%)$ & $\mathrm{S}(\%)$ \\
\hline TFC & 75.88 & 10.2 & 13.92 & 0 \\
TFN-1 & 74.49 & 11.44 & 13.72 & 0.34 \\
TFN-2 & 73.67 & 11.88 & 13.75 & 0.36 \\
TFN-4 & 72.2 & 9.69 & 17.73 & 0.38 \\
TFN-6 & 73.62 & 10.3 & 15.65 & 0.43
\end{tabular}

affected MPD's diffusion into the organic phase, and therefore restrained the formation of the ridge and valley structure. ${ }^{\mathbf{1 6}}$

To further investigate the reaction mechanism of the membranes' active layer, FTIR was performed. As shown in Fig. S2 (ESI $\dagger$ ), the characteristic peaks at $1658 \mathrm{~cm}^{-1}$ and $1543 \mathrm{~cm}^{-1}$ can be ascribed to the amide group formed by IP. The former may be the $\mathrm{C}=\mathrm{O}$ stretch of amide $\mathrm{I}$, whereas the latter may be ascribed to the $\mathrm{C}-\mathrm{N}$ stretch vibration of amide II, which proved that PA active layer was successfully synthesized. ${ }^{28}$ 




Ra: $71.1 \pm 3.6 \mathrm{~nm}$

$\mathrm{Ra}: 63.3 \pm 0.5 \mathrm{~nm}$
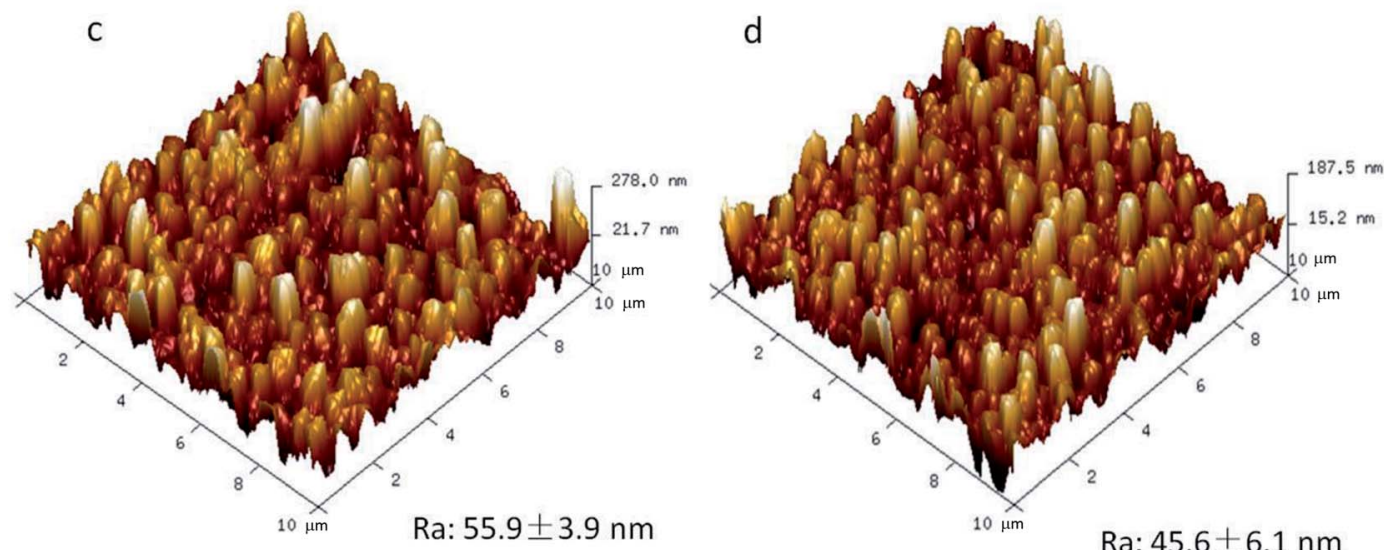

Ra: $45.6 \pm 6.1 \mathrm{~nm}$

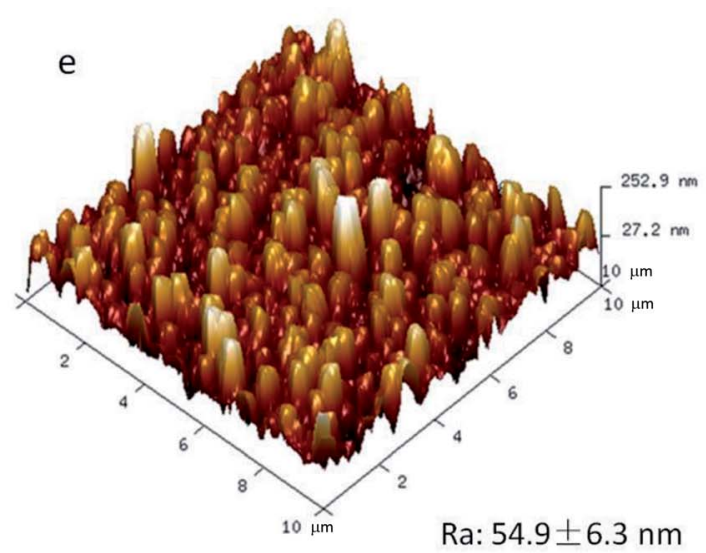

Fig. 4 AFM images of (a) TFC, (b) TFN-1, (c) TFN-2, (d) TFN-4 and (e) TFN-6 FO membranes.

As for the functional groups of SCNTs, no corresponding peaks were observed due to the minute incorporation of nanomaterials and the near over-lapping effect. However, XPS results in Table 1 depict that $S$ was detected in the PA layer of TFN membranes but not in the TFC membranes, proving that SCNTs were stable in the TFN membranes. The amount of $\mathrm{S}$ was proportional to the concentration of SCNTs in the MPD solution and achieved the highest content $(0.43 \%)$ when SCNT concentration was $600 \mathrm{ppm}$.

Fig. 4 shows the three dimensional AFM images of both modified and unmodified FO membranes. AFM analysis depicts that SCNTs truly affected the surface roughness of FO membranes. Compared to unmodified membranes (Fig. 4(a)), SCNTs-modified membranes were smoother and owned shorter surface lumps, the heights of which were in accordance with the 


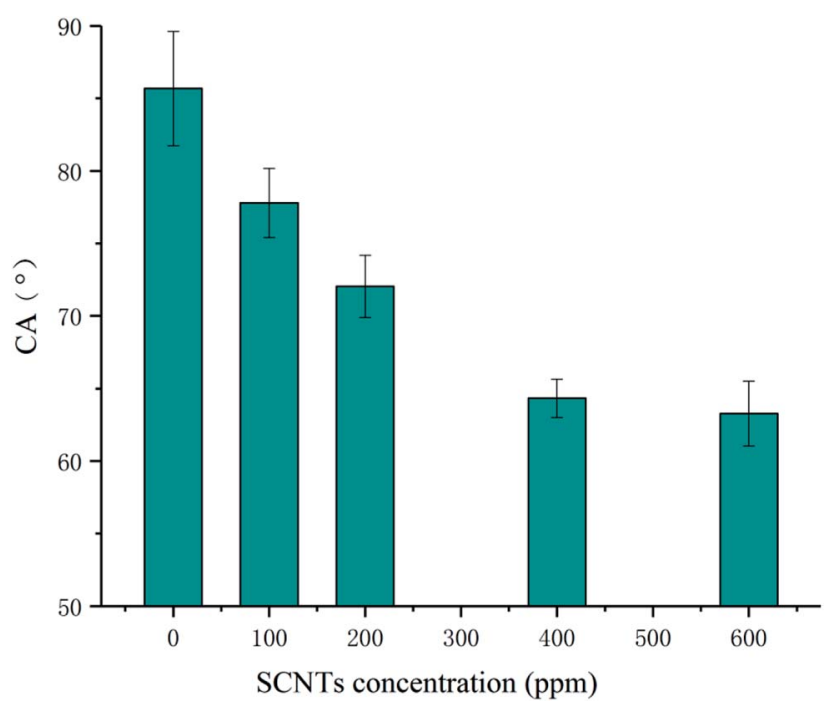

Fig. 5 Water contact angles of TFC and TFN membranes.

Table 2 Intrinsic transport properties of TFC and TFN membranes ${ }^{a}$

\begin{tabular}{llll}
\hline Membranes & $A\left(\mathrm{LMH} \mathrm{bar}{ }^{-1}\right)$ & $B(\mathrm{LMH})$ & $A / B\left(\mathrm{bar}^{-1}\right)$ \\
\hline TFC & $1.45 \pm 0.04$ & $0.24 \pm 0.01$ & $6.05 \pm 0.05$ \\
TFN-1 & $1.53 \pm 0.06$ & $0.22 \pm 0.01$ & $6.85 \pm 0.15$ \\
TFN-2 & $1.55 \pm 0.1$ & $0.2 \pm 0.01$ & $7.88 \pm 0.02$ \\
TFN-4 & $2.29 \pm 0.07$ & $0.23 \pm 0.03$ & $9.91 \pm 1$ \\
TFN-6 & $1.99 \pm 0.27$ & $0.21 \pm 0.05$ & $9.83 \pm 0.93$
\end{tabular}

${ }^{a} A$ represents water permeability of the membrane and $B$ is the salt permeability.

membranes' surface roughness. With the increase in the concentration of SCNTs, the surface lumps got shorter (Fig. 4(b)-(d)), which meant that the addition of SCNTs promoted smoother membranes. ${ }^{23}$ However, when the concentration of SCNTs was 600 ppm (Fig. 4(e)), the membranes' surface got rougher. This was probably because high-concentrated SCNTs would agglomerate easily, and thus increase the surface roughness. ${ }^{29}$ It was further proved by the mean roughness value $\left(R_{\mathrm{a}}\right)$ of membranes; SCNTs-modified FO membranes had lower $R_{\mathrm{a}}$ values than normal membranes, and TFN-4 membrane showed the lowest $R_{\mathrm{a}}$ of $45.6 \pm 6.1 \mathrm{~nm}$, which was significantly lower than that of TFC membrane $(71.1 \pm 3.6$ $\mathrm{nm})$.

Fig. 5 shows the CA values of all membranes. Unmodified TFC membrane exhibited the highest CA value, which revealed that it was the most hydrophobic one. CA values of modified membranes declined with the improvement in the concentration of SCNTs in MPD. The addition of SCNTs in the PA layer greatly enhanced the membrane's hydrophilicity. It can be explained from two aspects. First, SCNTs made the membrane surface more hydrophilic due to the sulfonic group. Besides, the addition of SCNTs made membrane surface smoother and improve its hydrophilicity.
Table 2 lists the transport parameters of TFC along with those of SCNTs-functionalized TFN FO membranes. It can be noted that TFN membranes exhibited better separation performance than the control membrane. For instance, the $A$ value of TFN-4 membrane is $2.29 \pm 0.07 \mathrm{LMH} \mathrm{bar}^{-1}$, which is markedly higher than that of TFC membrane $(1.45 \pm 0.04 \mathrm{LMH}$ bar $\left.^{-1}\right)$. Besides, the $B$ value even breaks the widely accepted trade-off phenomenon that increasing $A$ generally comes with higher $B$ values. $^{30}$ Functionalized TFN membranes on an average own lower $B$ values. One of the key properties of the active layer of TFC membrane is to maximize the $A / B$ ratio. ${ }^{31}$ As listed in Table 1 , TFN membranes exhibit higher $A / B$ ratio, and the value increased with the increase in SCNTs as a whole, which means that SCNTs-incorporated membranes exhibited better permselectivity in the FO mode. ${ }^{32}$

\subsection{Determination of FO performance}

Fig. 6 shows the FO performance of TFC and TFN membranes, including water flux $J_{\mathrm{w}}$, reverse salt flux $J_{\mathrm{s}}$ and $J_{\mathrm{s}} / J_{\mathrm{w}}$. As depicted, all SCNTs-functionalized membranes exhibited higher water flux than that of the control membrane. The flux of TFN-4 membrane was $29.9 \pm 1.6 \mathrm{LMH}$ compared to $21.3 \pm 2.1 \mathrm{LMH}$ for unmodified TFC membrane when DS was $1 \mathrm{M} \mathrm{NaCl}$ and FS was DI water, which showed a significant flux enhancement when SCNTs were incorporated. The flux of TFN membranes improved with the increase in the addition of SCNTs and achieved the highest value when the concentration of SCNTs was $400 \mathrm{ppm}$, which is in accordance with the results shown in Section 3.2. Enhanced hydrophilicity and decreased roughness might have partly contributed to this distinct improvement. Besides, not only the internal core of incorporated SCNTs but also the interfacial gap between SCNTs and polymer in the PA layer fabricated nanochannels for water transportation. It is worth mentioning that the external channel actually played a dominant role, since the internal core was too thin to extract water without impressed pressure. ${ }^{33,34}$

The reverse salt flux is also shown in Fig. 6(b). It is obvious that all the modified membranes exhibited a lower reverse salt flux than unmodified TFC membrane, and with the increase in of SCNTs' concentration, reverse salt flux decreased gently, showing an adverse trend with water flux. However, TFN-4 membrane exhibited an unusual salt flux which was higher than that of TFN-2 membrane and TFN-6 membrane. It might be due to the "permeability-selectivity trade-off" phenomenon, since TFN-4 membrane achieved an extremely high water flux. ${ }^{35}$

Furthermore, the impact of four kinds of DS concentrations on the membranes was also investigated. As shown in Fig. 6(a and $\mathrm{b}$ ), the water flux and reverse salt flux exhibited stable increase with the improvement of osmosis driving force, which was supplied by the DS. Specific reverse salt flux is also demonstrated in Fig. 6(c). It is actually the ratio of $J_{\mathrm{s}}$ and $J_{\mathrm{w}}$, which represents the solute mass loss of DS per unit volume of osmotic water. ${ }^{36}$ Its value is related to PA layer's permselectivity. Therefore, the $J_{\mathrm{s}} / J_{\mathrm{w}}$ ratio of TFN membrane was lower than that of TFC membrane averagely, whereas TFN-4 membrane showed the lowest $J_{\mathrm{s}} / J_{\mathrm{w}}$ value averagely. 

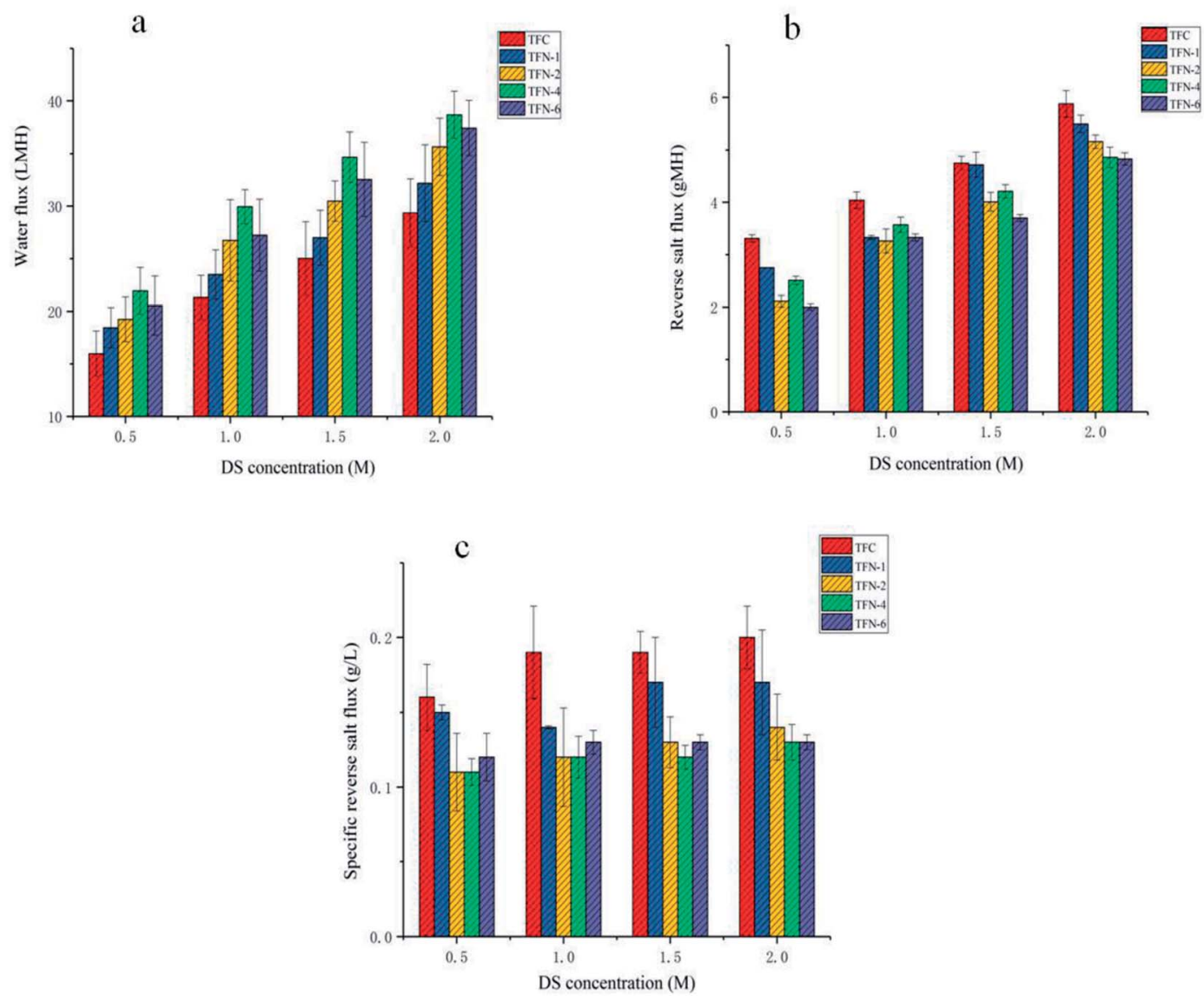

Fig. 6 Water flux (a), reverse salt flux (b) and specific salt flux (c) of TFC and TFN membranes.

\section{Conclusions}

In this study, novel SCNTs-incorporated TFN FO membranes were successfully fabricated and SCNTs' impact on membrane performance was also thoroughly investigated. The addition of SCNTs affects the hydrophilicity and roughness of PA layer as well as enhances the FO performance of TFN membranes. TFN4 membrane exhibited the highest water flux $(29.9 \pm 1.6 \mathrm{LMH})$ compared to unmodified TFC membrane $(21.3 \pm 2.1 \mathrm{LMH})$ without sacrificing the reverse salt flux. In general, SCNTsincorporated FO membranes exhibited potential application in FO technology because of their comprehensive superior separation properties.

\section{Conflicts of interest}

There are no conflicts of interest to declare.

\section{Acknowledgements}

This work is sponsored by Natural Science Foundation of Chongqing, China (No. cstc2018jcyjAX0362) and the National Natural Science Foundation of China (No. 51478452).

\section{References}

1 T. Cath, A. Childress and M. Elimelech, J. Membr. Sci., 2006, 281, 70-87.

2 S. Zhao, L. Zou, C. Y. Tang and D. Mulcahy, J. Membr. Sci., 2012, 396, 1-21.

3 Y. Xu, X. Peng, C. Y. Tang, Q. S. Fu and S. Nie, J. Membr. Sci., 2010, 348, 298-309.

4 R. L. McGinnis and M. Elimelech, Desalination, 2007, 207, 370-382.

5 C. R. Martinetti, A. E. Childress and T. Y. Cath, J. Membr. Sci., 2009, 331, 31-39.

6 B. Mi and M. Elimelech, J. Membr. Sci., 2010, 348, 337-345.

7 M. Xie, L. D. Nghiem, W. E. Price and M. Elimelech, Environ. Sci. Technol., 2013, 47, 13486-13493.

8 Y. Cui, Q. Ge, X.-Y. Liu and T.-S. Chung, J. Membr. Sci., 2014, 467, 188-194.

9 E. M. Garcia-Castello, J. R. McCutcheon and M. Elimelech, J. Membr. Sci., 2009, 338, 61-66.

10 T.-S. Chung, L. Luo, C. F. Wan, Y. Cui and G. Amy, Sep. Purif. Technol., 2015, 156, 856-860.

11 T.-S. Chung, S. Zhang, K. Y. Wang, J. Su and M. M. Ling, Desalination, 2012, 287, 78-81.

12 A. F. Faria, C. Liu, M. Xie, F. Perreault, L. D. Nghiem, J. Ma and M. Elimelech, J. Membr. Sci., 2017, 525, 146-156. 
13 X. Lu, S. Romero-Vargas Castrillon, D. L. Shaffer, J. Ma and M. Elimelech, Environ. Sci. Technol., 2013, 47, 12219-12228. 14 W. Xu, Q. Chen and Q. Ge, Desalination, 2017, 419, 101-116. 15 S. Liang, S. Xiong and Y. Wang, Chem. Eng. Sci., 2016, 143, 194-205.

16 X. Wu, R. W. Field, J. J. Wu and K. Zhang, J. Membr. Sci., 2017, 540, 251-260.

17 A. Zirehpour, A. Rahimpour, S. Khoshhal, M. D. Firouzjaei and A. A. Ghoreyshi, RSC Adv., 2016, 6, 70174-70185.

18 N. Ma, J. Wei, S. Qi, Y. Zhao, Y. Gao and C. Y. Tang, J. Membr. Sci., 2013, 441, 54-62.

19 A. Nguyen, L. Zou and C. Priest, J. Membr. Sci., 2014, 454, 264-271.

20 X. Song, L. Wang, L. Mao and Z. Wang, ACS Sustainable Chem. Eng., 2016, 4, 2990-2997.

21 Y. X. Jia, H. L. Li, M. Wang, L. Y. Wu and Y. D. Hu, Sep. Purif. Technol., 2010, 75, 55-60.

22 S. Beg, M. Rizwan, A. M. Sheikh, M. S. Hasnain, K. Anwer and K. Kohli, J. Pharm. Pharmacol., 2011, 63, 141.

23 A. Tiraferri, C. D. Vecitis and M. Elimelech, ACS Appl. Mater. Interfaces, 2011, 3, 2869-2877.

24 M. Amini, M. Jahanshahi and A. Rahimpour, J. Membr. Sci., 2013, 435, 233-241.

25 C. Y. Du, T. S. Zhao and Z. X. Liang, J. Power Sources, 2008, 176, 9-15.
26 A. Tiraferri, N. Y. Yip, A. P. Straub, S. Romero-Vargas Castrillon and M. Elimelech, J. Membr. Sci., 2013, 444, 523538.

27 M. J. Jablonsky, J. C. Yang and J. W. Mays, Polymer, 2002, 43, 5125-5132.

28 T. P. N. Nguyen, B.-M. Jun, J. H. Lee and Y.-N. Kwon, J. Membr. Sci., 2015, 495, 457-470.

29 J.-H. Choi, J. Jegal and W.-N. Kim, J. Membr. Sci., 2006, 284, 406-415.

30 G. M. Geise, H. B. Park, A. C. Sagle, B. D. Freeman and J. E. McGrath, J. Membr. Sci., 2011, 369, 130-138.

31 D. L. Shaffer, J. R. Werber, H. Jaramillo, S. Lin and M. Elimelech, Desalination, 2015, 356, 271-284.

32 Y. Zhao, X. Wang, Y. Ren and D. Pei, ACS Appl. Mater. Interfaces, 2018, 10, 2918-2928.

33 H. Ma, C. Burger, B. S. Hsiao and B. Chu, ACS Macro Lett., 2012, 1, 723-726.

34 G. Hummer, J. C. Rasaiah and J. P. Noworyta, Nature, 2001, 414, 188.

35 H. B. Park, J. Kamcev, L. M. Robeson, M. Elimelech and B. D. Freeman, Science, 2017, 356, 6343.

36 W. A. Phillip, J. S. Yong and M. Elimelech, Environ. Sci. Technol., 2010, 44, 5170-5176. 